\title{
Reproductive choice, enhancement, and the moral continuum argument
}

\author{
Erik Malmqvist
}

\section{Linköping University Post Print}

\section{Tweet}

N.B.: When citing this work, cite the original article.

This is an electronic version of an article published in:

Erik Malmqvist, Reproductive choice, enhancement, and the moral continuum argument, 2014, Journal of Medicine and Philosophy, (39), 1, 41-54.

Journal of Medicine and Philosophy is available online at informaworldTM:

http://dx.doi.org/10.1093/jmp/jht058

Copyright: Oxford University Press (OUP): Policy F / Taylor \& Francis http://www.oxfordjournals.org/

Postprint available at: Linköping University Electronic Press

http://urn.kb.se/resolve?urn=urn:nbn:se:liu:diva-103680 


\title{
REPRODUCTIVE CHOICE, ENHANCEMENT, AND THE MORAL CONTINUUM ARGUMENT
}

\author{
Erik Malmqvist \\ Linköping University
}

\begin{abstract}
For citing purposes, please use the final version of this article: E. Malmqvist, "Reproductive choice, enhancement, and the moral continuum argument," Journal of Medicine and Philosophy 2014;39: 41-54.
\end{abstract}

\begin{abstract}
It is often argued that it does not matter morally whether biomedical interventions treat or prevent diseases or enhance non-disease traits; what matters is whether and how much they promote wellbeing. Therapy and enhancement both promote wellbeing, the argument goes, so they are not morally distinct but instead continuous. I provide three reasons why this argument should be rejected when it is applied to choices concerning the genetic make-up of future people. First, it rests on too simple a conception of the badness of disease. Second, it wrongly assumes that diseaseavoidance and enhancement can proceed with similar accuracy. Third, it overlooks that disease-avoidance tends to be more urgent than enhancement from the point of view of distributive justice. While none of these reasons establishes a firm therapy-enhancement distinction, they show that a continuum model is not an attractive alternative.
\end{abstract}

Keywords: enhancement, reproductive choice, therapy-enhancement distinction, wellbeing 


\section{INTRODUCTION}

A major reason why genetics has received so much recent attention in popular culture, the media, and scholarly debates is that it offers increasing possibilities to choose who will be born. Individuals can employ a growing range of genetic tests in order to decide whether and with whom to procreate, whether to continue or terminate a pregnancy, or which among a set of embryos created through in vitro fertilization (IVF) to have implanted. The purpose of such testing is almost always to avoid giving birth to children with severely disabling diseases. However, much debate has focused on more exotic, if somewhat more remote, possibilities. It is widely speculated that the potential for using genetic tests to choose various non-disease traits for future people will expand as geneticists learn more about how genes influence these traits. And this potential will expand even further if techniques for altering the genetic make-up of embryos and gametes become more reliable than they currently are. To many it looks like biotechnology might give us the power to create children that are not only free from certain diseases, but also "enhanced" in various ways - stronger, smarter, cheerier, more sociable, and perhaps even morally better. Such prospects have provoked a range of reactions among bioethicists and other commentators: from alarm on one extreme to awe on the other, with cautious optimism and mild unease in between.

\section{THE MORAL CONTINUUM ARGUMENT}

Critics of offspring enhancement have typically appealed to the so-called therapyenhancement distinction in order to support their case. Genetic and other biomedical technologies may legitimately be used to avoid having children suffering from genetic 
diseases, they argue, but not to attempt to provide healthy children with enhanced capacities (Anderson, 1985; Habermas, 2003; President's Council on Bioethics, 2003). However, this distinction has come under increasingly heavy critique from enhancement advocates. One difficulty is conceptual in nature. If one wants to distinguish treating or preventing diseases from other interventions, one needs a clear definition of the term “disease", but such definitions are notoriously contested.

In this paper I will focus on another, normative argument against the therapyenhancement distinction. This argument relies on the claim that there is nothing morally special about treating or avoiding disease. We should welcome enhancements for the same reason that we already welcome treatments. In his recent book, Enhancing Evolution, John Harris writes:

The overwhelming moral imperative for both therapy and enhancement is to prevent harm and confer benefit. Bathed in that moral light, it is unimportant whether the protection or benefit conferred is classified as enhancement or improvement, protection or therapy. (Harris, 2007, 58)

Here is a rather typical quote from Julian Savulescu that makes the logic of the argument more explicit:

It is the goodness of health that drives a moral obligation to treat or prevent disease. Being healthy enables us to lead a good life. But health is not intrinsically valuable. It is instrumentally valuable - valuable as a resource that allows us to do what really matters, that is, lead a good life...[I]f it is well-being 
not health that is intrinsically valuable we can see why human enhancement can become a moral obligation. Many of our biological and psychological characteristics profoundly affect how well our lives go...If we have an obligation to treat and prevent disease, we have an obligation to try to manipulate these characteristics to give an individual the best opportunity of the best life. (Savulescu, 2005, 37-38)

What Harris, Savulescu, and others argue, then, is that concern for our future children's wellbeing should make us want to enhance them, not just make sure that they do not suffer from disease. ${ }^{i}$ From the point of view of wellbeing, there can be no distinction between therapy and enhancement; instead, they should be thought of as morally continuous. ${ }^{\text {ii }}$

While Harris's and Savulescu's views on offspring enhancement have been vigorously attacked in recent bioethical literature (De Melo-Martín, 2004; Parker, 2007; Malmqvist, 2011; Sparrow, 2011), this elegant and powerful argument, "the moral continuum argument" as I shall call it, has not yet sustained systematic critique. This paper provides such a critique. My aim is to offer reasons to resist thinking of therapy and enhancement as morally continuous in the context of reproductive decisionmaking. Such thinking, I shall suggest, rests on too simple a conception of the badness of disease, overlooks the importance of risks and uncertainties, and fails to take distributive justice seriously. I will not go so far as to positively defend a full-fledged therapy-enhancement distinction, only suggest that the alternative continuum model is flawed. 
Before going into the details of my critique, allow me to say something about the nature of the argument I challenge. When enhancement advocates claim that therapy and enhancement are morally continuous, they are not just making an abstract point about human wellbeing. More precisely, they are not only saying that having enhanced capacities might contribute as much as freedom from disease to somebody's life going well. They also believe that important practical conclusions follow from that claim. Both Harris (2009) and Savulescu (2001a; 2001b; 2005; 2007; Savulescu and Kahane, 2009) believe that insofar as enhancements can be expected to advance children's wellbeing, prospective parents are morally obligated to pursue them. Once safe and effective means for improving future offspring are readily available, reproducers will act wrongly if they do not use them - just like they now act wrongly if they fail to use safe, effective, and not too costly existing techniques to ensure having healthy rather than disabled children. The nature of the wrong is the same in both cases: a failure to promote the wellbeing of the resulting child. ${ }^{\text {iii }}$

The practical implications of the moral continuum argument stretch far beyond individual reproductive choices. If a concern for wellbeing is important enough to entail that prospective parents are morally obligated to enhance their offspring, it is difficult to see why it does not also entail that other parties should take an active role in the pursuit of such enhancement. The wellbeing of future children is likely to be more effectively promoted through shared rather than merely individual efforts. To be sure, unlike the eugenicists of the past, contemporary enhancement advocates do not recommend state coercion for the sake of better offspring; to the contrary, they identify themselves as champions of reproductive liberty. ${ }^{\text {iv }}$ However, Savulescu (2001a, 425) argues that the moral obligation to enhance justifies persuading people to test for and 
select beneficial non-disease genes. And Harris (2007) defends enhancement as a broad, societal endeavor aimed at improving the human lot. Such recommendations make perfect sense in view of the kind of argument these authors employ. If enhancements are indeed morally continuous with treating and preventing disease, health professionals and policy makers seem to have strong reason to attribute similar importance to them that is, to inform people about them, encourage their use, allocate considerable resources to enhancement research and development, and so on. In short, the moral continuum argument underpins a broad, practical pro-enhancement program. I believe that it should be assessed accordingly.

\section{SITUATING THE CRITIQUE}

It should be clear from what I have said already that the argument I am discussing is consequentialist in nature. Consequentialists think that we should act so as to bring about what is intrinsically good or valuable: wellbeing, happiness, or utility. And most of them hold that we should bring about as much of it as possible. Like other consequentialist arguments, the moral continuum argument proceeds from a claim about value to a claim about how we ought to act. It moves from the claim that therapy and enhancement offer equal or comparable benefits to the claim that we should enhance, not just treat or avoid disease. Once this basic structure is made explicit, three possible avenues for critique open up. First, one may challenge the value claim by denying that therapy and enhancement offer the same sort of benefits. Second, one may challenge the move from the value claim to the practical claim - that is, one may argue that even if therapy and enhancement are equally beneficial it does not follow that there are equally 
strong reasons to pursue them. Third, one may reject the whole consequentialist enterprise of grounding moral obligations in valuable outcomes.

I will not pursue the last and most ambitious strategy here. There are different non-consequentialist approaches to the ethics of reproductive choice in the literature (Wasserman, 2005; McDougall, 2007), but I want to challenge the moral continuum argument from within the broadly consequentalist framework that the argument itself relies on. Such a critique is potentially more damaging than a critique proceeding from an altogether different theoretical framework. I will begin by outlining an objection belonging to the first strategy: there are reasons to think that therapy and enhancement confer qualitatively different benefits (section IV). In keeping with my understanding of the moral continuum argument as a practical argument, I will then advance two objections belonging to the second strategy: even if we grant that therapy and enhancement may offer equal benefits, we should still treat them differently out of concern for risks and uncertainties (section V) and for distributive justice (section VI).

\section{HEALTH AND WELLBEING}

What counts as a benefit to a person depends on what wellbeing, a good life, or human flourishing is. Now that question is of course as old as philosophy itself. There is no consensus on what the good life ultimately consists in; the main contenders are pleasurable experiences, preference satisfaction, and the possession of different “objective goods" (Parfit, 1984, Appendix I). However, there is at least some mid-level agreement on certain important ingredients in such a life. Theorists tend to converge, although for different reasons, on the idea that a good life is to a considerable extent a life one chooses and realizes for oneself. That is, they typically emphasize the important 
role of personal autonomy - in the broadest sense of the term - for human flourishing. Objectivists are likely to regard this role as constitutive: autonomous choice and pursuit of different ends are an irreducible part of a full human life. ${ }^{\mathrm{v}}$ Inspired by John Stuart Mill's (1978) conviction that people as a rule know their own interests better than others do, hedonists and preferentialists instead tend to think of autonomy as instrumentally related to the good. In either case, benefitting people in ways that increase their chances of living autonomously is of special importance.

Although I do not want to generalize too much, I think that curing and preventing illness are more likely than enhancements to benefit people in such ways. The profoundly incapacitating nature of illness constitutes a recurrent theme in the philosophy of medicine. According to one leading group of theories, the link between illness and incapacity is even conceptual; when we are ill we are by definition unable to do a great number of things (Fulford, 1989; Nordenfelt, 1995). In particular, we are unable to do things that matter much to how our lives go, unable to achieve for ourselves what we need to flourish (Nordenfelt, 1995). Correspondingly, curing and preventing illness expand people's capacity to themselves realize flourishing lives. The question could of course be raised whether the same thing could not be said about enhancement. Consider an example. If I move to a foreign country I may be unable to learn the new language quickly enough to participate in social and professional life, and I may suffer greatly as a result. Do not my ordinary (healthy) cognitive limitations constitute an obstacle to my flourishing in precisely the way that illness does? And would not enhancing my cognition so as to speed up my learning help removing such an obstacle in precisely the way that cures for illness do? Not quite. If my incapacity were due to a cognitive disorder instead of an ordinary limitation - if I 
were $i l l$, not just $d u l l$ - I would not merely be unable to learn the language as quickly as I would like. Also, significant progress would remain out of reach no matter how hard I studied or how good a teacher I hired. In Lennart Nordenfelt's (1995) terms, not only would I lack the desired ability to communicate; I would lack the very ability to acquire that ability in ways that people normally do. My inability would be, as he puts it, of a second-order kind. But because I am in fact not ill but merely dull, my inability is of a first- rather than a second-order kind. It can be overcome by engaging in appropriate training. One can appreciate the general point whatever one thinks of Nordenfelt's particular way of conceptualizing it: illness is not incapacitating in quite the same way as other human limitations, but involves incapacity of an especially profound kind.

If this is right, then enhancement advocates have failed to appreciate the difference between health and other goods and between illness and other harms. Health is a special, because particularly autonomy-conducive, good; and illness is a special, because particularly autonomy-inhibiting, harm. This implies that benefiting people by protecting or restoring their health is in one important respect morally more weighty than benefiting them in other ways. Insofar as parents want their children not just to flourish, but to be able to flourish through their own choices and pursuits, they have special reason to make sure that they are born healthy. However, while this argument stresses the value of health, it does not entail a sharp therapy-enhancement distinction. This is partly because it does not deny the value of capacities other than health and partly because some enhancements are arguably themselves health promoting and thus beneficial in the same way that therapy is. ${ }^{\mathrm{vi}}$ What it does entail is that therapy and enhancement are not simply continuous either. 


\section{RISKS, UNCERTAINTIES, AND ABSTRACTION}

I now turn to the second form of critique that one may direct against the moral continuum argument. What I want to argue now is not that therapy and enhancement offer different sorts of benefits, but that even if they do benefit people equally it does not follow that there are equally strong reasons to pursue them. The moral continuum argument, I believe, moves too quickly from the claim that enhanced capacities benefit people to the claim that we ought to enhance.

It is useful to begin by recalling a familiar point about consequentialism. Aiming at the best consequences may be a poor way of actually bringing about the best consequences. If available means to the greatest good are inefficient or unsafe, opting for a lesser but more reachable good will often be a better consequentialist strategy. One needs to consider not only the value of the outcome one aims for, but also the probability of realizing that outcome as well as the value and probability of possible side effects. So if we want to promote our future children's wellbeing we should not only make sure that the traits we seek to endow them with are genuinely beneficial. We should also make sure that our attempts to produce these traits are sufficiently safe and likely to succeed.

This may seem like a trivial point, and enhancement advocates are quick to concede it. Nobody defends enhancing children when doing so would expose them to great risks or be unlikely to succeed. Harris $(2007,9,33)$ stresses that, like therapy, enhancement should only proceed when the magnitude and probability of the benefits make the risks worth taking. Similarly, but in slightly more technical terms, Savulescu and Kahane $(2009,281)$ explain that reproductive choices should maximize the expected wellbeing of the resulting child. ${ }^{\text {vii }}$ However, once that much is conceded it is 
difficult to see how the moral continuum argument can get off the ground. For sustaining that argument requires showing that enhancements are continuous with therapies not only with respect to the size of the benefits they offer, but also with respect to the likelihood with which these benefits can be produced.

This latter claim seems exceedingly strong, at least given the current state of science and technology. The traits that are typically put forward as candidates for enhancement - self-control, intelligence, physical strength, and so on - are highly complex, determined by an intricate interplay between many different genes and environmental factors. And our knowledge of that interplay is highly limited with respect to any such trait. So selecting or manipulating a particular genetic combination assumed to correlate with some attractive trait in an embryo will usually be an exceedingly uncertain way of actually bringing about that trait in the future child. ${ }^{\text {vii }}$ By contrast, the genetic disorders that are currently selected against are typically the result of much simpler and better-understood causal mechanisms, making the chance of success much larger.

Such concerns about uncertainty are familiar, of course, and admittedly a bit unexciting. Moreover, there is standard response to them: they are contingent on current scientific and technological limitations. Imagine away these limitations and the concerns disappear as well. Enhancement advocates proceed from the (explicit or implicit) assumption that our knowledge of how genes influence complex traits will vastly grow; indeed, they sometimes write as if such advances had already been made. In effect, the question they pose is the following: suppose that we could choose attractive traits for future children as accurately as we now select against certain diseases, then what is the problem? Now abstractions of this sort certainly have a place 
in the philosopher's repertoire. Abstractions are useful when they allow us to set aside contingent features of messy real world situations that distract attention from or conceal what is really important. However, abstractions can also work the opposite way, by themselves distracting us from or concealing what is important.

The abstraction employed here seems to me to be of this latter type. One crucial thing that it conceals is the vast difference between the interventions we are asked to compare. On one extreme there is selection against single-gene disorders with complete or high penetrance, such as Tay Sachs or Huntington's, where one can be almost certain that any person developing from an embryo with the mutation will eventually suffer from the disease. On the other extreme there is selection of, say, intelligence, a trait whose very definition is controversial and that on any plausible definition is composed of a large number of component traits, each of which determined by a highly complex interaction between a large number of genes and environmental factors. To assume that we can choose intelligence with a degree of accuracy comparable to that with which we select against Tay Sachs may be a useful theoretical exercise if we want to think clearly about the nature of human wellbeing. But it looks more like a misleading fantasy if we are interested in any practical question pertaining to such choices - whether, say, selection for intelligence should ever be attempted by parents, recommended by doctors, or permitted by law. The simple reason why the assumption is misleading in these contexts is that it is unlikely in the extreme that it will ever be true. Insofar as enhancement advocates are ultimately interested in practical questions, they help themselves to more abstraction than they are entitled to.

But let us indulge in this sort of abstraction for a moment. Suppose we knew everything there is to know about all the genes involved in some attractive 
complex trait - the full causal effects of each gene not only on the trait in question but also on all other affected traits. And suppose there were tests available for detecting each of these genes in IVF embryos. Could we not then select the trait with a very high degree of accuracy? Now since any phenotypic trait is caused by gene-environment interaction we would not be choosing the trait itself but a predisposition - a probability to develop the trait across a range of environments. ${ }^{\text {ix }}$ But would we not at least be selecting a very carefully defined such probability? And would that not increase the expected wellbeing of the child just as accurately as selection against a genetic disorder does?

I believe that the answer is "no". There is a further important difference between the two kinds of selection, a difference that remains even if we imagine away all current scientific and technological limitations. ${ }^{\mathrm{x}}$ Traits like self-control, intelligence, and physical strength are gradually shaped through complex social practices - rearing, education, training, and so on. These practices do not only provide the necessary environment in which the genetic potential for these traits is realized. They are also the context in which crucial questions about the value of the traits are posed and grappled with. Parents do not set out rearing a child with a fixed view of precisely how much self-control (say) - as opposed to potentially competing traits, like spontaneity - the child should possess. Rather, this view is formed and revised in the process of cultivating the trait in interaction with the child itself, through gradually learning about and adjusting one's efforts to the child's particular potentials and limitations, wishes and aversions. The point is not that self-control does not benefit the child. The point is rather that the detailed, highly contextual knowledge required to accurately shape that trait is simply unavailable when the child is still an embryo - and would remain 
unavailable even in some imagined future scenario where knowledge about genetic causation is perfect. The same goes for any other beneficial trait that comes in degrees and potentially competes with other attractive characteristic. Standard cases of selection against disease seem different. One does not need to rear a child for years to know that Tay Sachs or cystic fibrosis would be inimical to its flourishing.

I am not suggesting that this difference maps perfectly onto the therapyenhancement distinction. Sometimes it cannot be assumed that a condition normally regarded a disorder would inhibit a child's flourishing without considering what that child's life story would be like. ${ }^{\mathrm{xi}}$ Conversely, certain enhancements could perhaps be assumed to benefit future people quite independently of any social shaping process. (Increased disease resistance comes to mind here.) However, as a general matter, it cannot simply be assumed that selection of genes correlated with traits like intelligence, self-control, and physical strength could ever benefit future people with the same accuracy as selection against disease genes does. That assumption overlooks the crucial role that practices like rearing and education play in ascertaining that such traits are cultivated in beneficial ways. It is important not to idealize these practices, of course; they sometimes end up doing more harm than good. But they cannot simply be abstracted away for the purposes of ethical argument.

\section{DISTRIBUTIVE JUSTICE}

There is a further, justice-based objection against the moral continuum argument. Even if we assume that disease-avoidance and enhancement offer equal benefits (which I questioned in section IV) and that these benefits can be achieved with equal accuracy (which I questioned in section V), it does not follow that there are equally strong 
reasons to pursue them. If we care about distributive justice we should still regard disease-avoidance as generally more important. Or so I shall argue in this section.

Much of the literature on offspring enhancement and justice has focused on two concerns (Buchanan et al., 2000; De Melo-Martín, 2004; Singer, 2009; Wilkinson, 2010). First, if access to enhancement technologies depends on ability to pay, the better off will be able to give their children advantages that are unavailable to the worse off, thus increasing social inequalities. The second concern is about enhancement of "positional goods", that is, traits that benefit a person only because they give her a competitive edge over others. If some parents give their children such an advantage they simultaneously disadvantage other children who do not get it, which is unfair. Providing everyone with the advantage, on the other hand, is self-defeating; nobody gains because everyone's position relative to others remains unchanged. (Wilkinson, 2010, 199) Neither concern distinguishes systematically between avoiding disease and enhancing capacities. The first applies as much to therapy as to enhancement; the second applies only to some enhancements, not to enhancement in general. So neither looks like a promising starting point for an objection to the moral continuum argument.

I would like to make a different, simpler point about justice and offspring enhancement, a point that does help us mount an objection to that argument. Distributive justice is a deeply contested concept. However, despite profound theoretical differences many philosophers convergence on the very broad idea that justice requires special concern for the least advantaged. They agree that it is more important to make sure that those who are worst off with respect to key goods - such as resources, capabilities, or wellbeing - do not fall too far behind than to secure such 
goods for the better off. John Rawls's (1971) difference principle, the prioritarian view that wellbeing improvements are more valuable the worse off those who enjoy them are (Arneson, 2000), and the sufficitarian notion that each citizen ought to be guaranteed a minimum level of central capabilities (Nussbaum, 2000) all capture some version of this idea.

If one cares about justice in this very broad sense, one has reason to be suspicious of the moral continuum argument. One should want to make a fairly systematic - although not a categorical - moral difference between avoiding creating children with genetic diseases and seeking to create children with enhanced capacities. The simple reason is that, other things being equal, a person born with a genetic disease rather than healthy can be expected to fare worse than a person born healthy but with normal rather than enhanced capacities. Whether measured on a scale of resources, wellbeing, or capabilities, a disease is likely to make a person more disadvantaged than the lack of some enhancement is. Accordingly, avoiding diseases will more reliably than securing enhancements prevent people from scoring low on such a scale; enhancements are more prone to placing people high above rather than close to the average. So disease-avoidance looks more important than enhancement from the point of view of justice, even if the two offer equally large benefits.

This is a simple argument but it needs some clarification. First, as should be clear already, it is compatible with different views concerning what should be distributed fairly. It does not matter much, I believe, whether the "currency" of distributive justice is resources, capabilities, or wellbeing because diseases generally make people fare worse in all these respects. ${ }^{\text {xii }}$ Second, the argument is better understood as being about social policy than about individual morality. It is not clear 
that prospective parents should care much about the distribution of benefits between people; the good of their child should arguably be their main concern. The idea that policy makers should take distributive justice into account when deciding, for instance, what genetic tests to subsidize or what sorts of biotechnological research and innovation to encourage looks much more attractive.

Third, the argument I have outlined is not properly speaking an argument against enhancement. It only says that avoiding disease is generally more important. Exceptions suggest themselves if one takes into account the distribution of goods more broadly. In a context where large social inequalities obtain, considerations of justice may favor providing the badly off with enhancements over providing therapies for those who are expected to fare well whether they receive these therapies or not. This is especially likely to be the case if the better off already enjoy the enhancements in question. Offering therapies to the worse off is likely to be an even higher priority in such circumstances, however, because suffering from disease is likely to make their lives worse than lacking enhanced capacities. Not even that may always be true, of course; it is possible that the worse off could be more effectively helped by some significant enhancement than by therapy for some mild or moderate disease. While I recognize that there are such exceptions, I believe that they are just that - exceptions. They should not make us overlook the general point. Because diseases tend to make for lives with lower wellbeing or fewer capabilities or resources than the lack of enhancement, a concern for justice should make us want to make a fairly systematic moral difference between avoiding diseases and enhancing capacities.

\section{CONCLUDING REMARKS}


It is often argued that it does not matter morally whether biomedical interventions treat or prevent diseases or enhance non-disease traits; what matters is whether and how much they promote wellbeing. Therapy and enhancement both promote wellbeing, the argument goes, so they are not morally distinct but instead continuous. I have provided three reasons why this argument should be rejected when it is applied to choices concerning the genetic make-up of future people. First, it rests on too simple a conception of the badness of disease. Second, it wrongly assumes that diseaseavoidance and enhancement can proceed with similar accuracy. Third, it overlooks that disease-avoidance tends to be more urgent than enhancement from the point of view of distributive justice. While none of these reasons establishes a firm therapy-enhancement distinction, they show that a continuum model is not an attractive alternative.

While I have focused on reproductive choices, it is notable that the moral continuum argument has broader application. Indeed, it can be invoked in favor of all kinds of biomedical enhancement. Much of my critique of that argument also seems to apply more broadly. If health is a special good, then it requires special concern outside the reproductive context as well. By contrast, some of the uncertainties that I have claimed pertain to offspring enhancement are peculiar to that context. Because such interventions target an embryo they cannot rely on to the detailed, contextual knowledge that successful shaping of traits through rearing, education, and training presupposes. Other biomedical enhancements need not be as uncertain if they are employed as part of such broader practices. However, insofar as they are expected to replace rather than complement the cultivation of traits through gradual, flexible, and self-reflective social means, concerns about uncertainty may apply. As to distributive justice, whether diseases disadvantage people more than the lack of enhancement does clearly varies 
from one context to another. It is plausible to think that they sometimes do, however, and when they do there will be a prima facie reason for favoring therapy and prevention over enhancement. While worthy of further investigation, these issues are clearly too large to be treated more systematically in this paper.

It bears repeating that nothing I have said implies a wholesale rejection of biomedical enhancement, either in the context of reproduction or elsewhere. To say that health is a special good is not to deny the value of other goods; to say that these other good are harder to attain is not to deny that they should be pursued at all; and to say that avoiding disease is often more important than enhancing capacities from the point of view of justice is not to deny that justice might also sometimes require enhancement. My arguments thus fall well short of establishing a therapy-enhancement distinction, understood as a distinction between the permissible and the impermissible. The difficulties with such line drawing are well known. What I hope to have shown is that that thinking of therapy and enhancement as morally continuous is not very attractive either. 
i This argument appears frequently in Harris's and Savulescu's work on enhancement. In addition to the works already cited, see Harris (1999, 167-169), Harris (2001, 386), Harris (2009, 131, 150-151), Bortolotti and Harris (2006, 37-39), Savulescu (2001a, 419-421), Savulescu (2001b, 86), Savulescu (2007, 284), and Savulescu and Kahane (2009, 276-277). The same line of reasoning is found in the works of other authors, too (Glover, 2006, 75-76; Wilkinson, 2010, 195-196).

${ }^{\text {ii }}$ I follow Harris $(2007,4)$ in speaking of a continuity or continuum between therapy and enhancement. Harris believes that the reason for thinking of therapy and enhancement as continuous is that there is a continuum between avoiding harm and conferring benefit (Bortolotti and Harris 2006, 37-39). Addressing the idea of such a broader continuum would require a more thorough examination of the concept of harm than I have space for here. Moreover, I am not sure that addressing that idea would contribute much to my discussion of the alleged therapy-enhancement continuum; it is not clear that therapy and enhancement fit neatly into the broader categories of avoiding harm and conferring benefit.

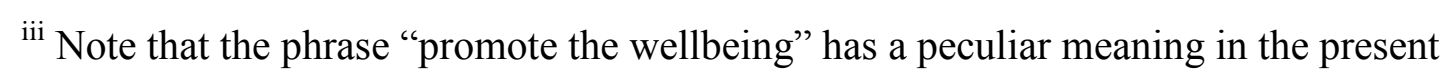
context. Many of the choices under discussion (e.g. choices between different embryos) cause one person to exist rather than another. It is therefore not clear that they can be said to benefit the person in the ordinary sense of making her better off than she otherwise would have been. If a different choice had been made she would not enjoy a life of lower wellbeing; someone else would exist instead. Similarly, such identityaffecting choices normally cannot be said to harm the person created, and it is debatable whether they can constitute therapy or enhancement. Derek Parfit (1984) has famously 
noted that choices of this sort raise vexing problems for ethical theory. To keep things simple I do not address these problems here. I shall assume that we can speak of harm, benefit, therapy, and enhancement without comparing a person's life to that same person's life on some alternative course of action.

${ }^{\text {iv }}$ See Harris (2007, ch. 5), Savulescu (2001a, 425), and Savulescu (2002). One may wonder, however, just how robust enhancement advocates' support for reproductive liberty can be. If one's ultimate moral commitment is to the advancement of wellbeing it is difficult to deny that coercive interference with reproductive choices might be justified when very much wellbeing is at stake (Sparrow, 2011).

` This idea figures prominently in, for instance, Martha Nussbaum's (2000) version of the capabilities approach.

${ }^{\text {vi }}$ Harris offers some examples that might qualify as health promoting enhancement, including the introduction of "genes coding for antibodies to major infections, or coding for repair enzymes which would correct the most frequently occurring defects caused by radiation damage, or which might remove predispositions to heart disease, or which would destroy carcinogens" (Harris, 1998, 220).

vii The expected value of an outcome is its value multiplied by the probability of its occurrence.

${ }^{\text {viii }}$ For more on the difficulties involved here, see Daniels (2009).

${ }^{\text {ix }}$ Likewise, selection against Tay Sachs and other single-gene disorders is strictly speaking selection against a predisposition; the difference is just that the probability of developing the illness is very high and the environmental range very broad.

${ }^{\mathrm{x}}$ This paragraph draws on an argument that I have developed at greater length elsewhere (Malmqvist, 2011). 
${ }^{x i}$ Deaf parents might, for instance, reasonably deny that a deaf child of theirs would have worse life prospects than a hearing child on the grounds that they would be better parents to a deaf child (Sparrow, 2002, 15).

${ }^{\text {xii }}$ At least this is the case if we think of a person's resources as including not only her material goods but also her abilities and talents. Allen Buchanan and colleagues have convincingly demonstrated that such an inclusive conception of resources is hard to resist once choices concerning people's genetic make-up are possible (Buchanan et al., 2000, 76-79). 


\section{REFERENCES}

Anderson, W.F. 1985. Human gene therapy: Scientific and ethical considerations. Journal of Medicine and Philosophy 10: 275-291.

Arneson, R. 2000. Luck egalitarianism and prioritarianism. Ethics 110: 339-349.

Bortolotti, L., and J. Harris. 2006. Disability, enhancement and the harm-benefit continuum. In: Freedom and responsibility in reproductive choice (pp. 31-49), J.R. Spencer, and A. Pedain (eds). Portland, OR: Hart Publishers.

Buchanan, A., D.W. Brock, N. Daniels, and D. Wikler. 2000. From chance to choice: Genetics and justice. Cambridge: Cambridge University Press.

Daniels, N. 2009. Can anyone really be talking about ethically modifying human nature? In: Human enhancement (pp. 25-42), J. Savulescu, and N. Bostrom (eds). Oxford: Oxford University Press.

De Melo-Martín, I. 2004. On our obligation to select the best children: A reply to Savulescu. Bioethics 18: 72-83.

Fulford, K.W.M. 1989. Moral theory and medical practice. Cambridge: Cambridge University Press.

Glover, J. 2006. Choosing children: The ethical dilemmas of genetic intervention. Oxford: Oxford University Press.

Habermas, J. 2003. The future of human nature. Cambridge: Polity.

Harris, J. 1998. Clones, genes, and immortality: Ethics and the genetic revolution. Oxford: Oxford University Press.

Harris, J. 1999. Is gene therapy a form of eugenics? Reprinted in Bioethics: An anthology (pp. 165-170), H. Kuhse, and P. Singer (eds). Oxford: Blackwell.

Harris, J. 2001. One principle and three fallacies of disability studies. Journal of Medical Ethics 27: 383-387. 
Harris, J. 2007. Enhancing evolution: The ethical case for making better people. Princeton: Princeton University Press.

Harris, J. 2009. Enhancements are a moral obligation. In: Human enhancement (pp. 131-154), J. Savulescu, and N. Bostrom (eds). Oxford: Oxford University Press. Nussbaum, M.C. 2000. Women and human development. Cambridge: Cambridge University Press.

Malmqvist, E. 2011. Reprogenetics and the "parents have always done it" argument. Hastings Center Report 41(1): 43-49.

McDougall, R. 2007. Parental virtue: A new way of thinking about the morality of reproductive actions. Bioethics 21: 181-190.

Mill, J.S. 1978 [1859]. On liberty. Indianapolis, Ind.: Hacket.

Nordenfelt, L. 1995. On the nature of health: An action-theoretic approach. $2^{\text {nd }}$ rev. ed. Dordrecht: Kluwer.

Parfit, D. 1984. Reasons and persons. Oxford: Oxford University Press.

Parker, M. 2007. The best possible child. Journal of Medical Ethics 33: 279-283.

President's Council on Bioethics. 2003. Beyond therapy: Biotechnology and the pursuit of happiness. New York: HarperCollins.

Rawls, J. 1971. A theory of justice. Cambridge: The Belknap Press of Harvard University Press.

Savulescu, J. 2001a. Procreative beneficence: Why we should select the best children. Bioethics 15: 413-426.

Savulescu, J. 2001b. Why genetic testing for genes for criminality is morally required. Princeton Journal of Bioethics 4: 79-97.

Savulescu, J. 2002. Deaf lesbians, "designer disability," and the future of medicine. British Medical Journal 325: 771-773. 
Savulescu, J. 2005. New breeds of humans: The moral obligation to enhance.

Reproductive Biomedicine Online 10 (suppl. 1): 36-39.

Savulescu, J. 2007. In defence of procreative beneficence. Journal of Medical Ethics 33: $284-288$.

Savulescu, J., and G. Kahane. 2009. The moral obligation to create children with the best chance of the best life. Bioethics 23: 274-290.

Singer, P. 2009. Parental choice and human improvement. In: Human enhancement (pp. 277-289), J. Savulescu, and N. Bostrom (eds). Oxford: Oxford University Press.

Sparrow, R. 2002. Better off deaf? Res Publica 11(1): 11-16.

Sparrow, R. 2011. A not-so-new eugenics: Harris and Savulescu on human enhancement. Hastings Center Report 41(1): 32-42.

Wasserman, D. 2005. The non-identity problem, disability, and the role morality of prospective parents. Ethics 116: 132-152.

Wilkinson, S. 2010. Choosing tomorrow's children: The ethics of selective reproduction. Oxford: Oxford University Press. 